\title{
Age of acquisition, word frequency, and the role of phonology in the lexical decision task
}

\author{
SIMON GERHAND and CHRISTOPHER BARRY \\ Cardiff University, Cardiff, Wales
}

\begin{abstract}
In five experiments, we examined the respective roles of word age of acquisition (AoA) and frequency in the lexical decision task. The two variables were manipulated orthogonally (while controlling for concreteness and length) in fully factorial designs. Experiment 1 was a conventional lexical decision task, and Experiments 2-5 involved various attempts to interfere with reliance upon phonology. In Experiment 2, only orthographically illegal nonwords were used; in Experiment 3, pseudohomophone nonwords; in Experiment 4, articulatory suppression by the recitation of a nursery rhyme; and in Experiment 5, articulatory suppression by the repetition of a single word. The same basic pattern of results was observed in all experiments: There were main effects of both AoA and frequency, which interacted in such a way that the AoA effect was larger for low- than for high-frequency words. Although the AoA effect was reduced by manipulations intended to interfere with phonological processing, the manipulations did not eliminate the effect. The results are discussed in terms of current models of reading in which it is proposed that AoA has its primary effect on the retrieval of lexical phonology, which appears to be consulted automatically in the lexical decision task.
\end{abstract}

A recently growing body of research has been focused on the attempt to separate the effects of age of acquisition (AoA) and word frequency in lexical processing tasks. The two variables are correlated, since words acquired early in life tend to occur commonly in adulthood. Recent studies have been concerned with the possibility that the very many reported effects of frequency might be confounded with the effects of AoA. The effects of AoA have been demonstrated in studies of picture naming latencies (see, e.g., Barry, Morrison, \& Ellis, 1997; Carroll \& White, 1973; Lachman, Shaffer, \& Hennrikus, 1974; Morrison, Ellis, \& Quinlan, 1992), word naming latencies (e.g., Brown \& Watson, 1987; Gerhand \& Barry, 1998; Gilhooly \& Logie, 1981a; Morrison \& Ellis, 1995), and lexical decision latencies (e.g., Morrison \& Ellis, 1995; Turner, Valentine, \& Ellis, 1998). Many studies have reported the effects of word frequency on picture naming latencies (e.g., Humphreys, Riddoch, \& Quinlan, 1988; Jescheniak \& Levelt, 1994; Oldfield \& Wingfield, 1965), word reading latencies (e.g., Forster \& Chambers, 1973; Frederiksen \& Kroll, 1976; Grainger, 1990; Monsell, Doyle, \& Haggard, 1989; Strain, Patterson, \& Seidenberg, 1995), and lexical decision latencies (e.g., Allen, McNeal, \& Kvak, 1992; Forster \& Chambers, 1973; and many others). However, these studies have typically not taken AoA into account. Studies that have looked for AoA ef-

The first author was supported by a Medical Research Council (U.K.) studentship. We are indebted to the programming expertise of Alan Milne. We thank Bob Lorch and three anonymous reviewers for their helpful comments on an earlier draft. Correspondence concerning this article should be addressed to C. Barry, School of Psychology, Cardiff University, P.O. Box 901, Cardiff, CF1 3YG, Wales (e-mail: barry@cardiff.ac.uk). fects in tasks that do not require spoken word production, such as auditory and visual word recognition thresholds (Gilhooly \& Logie, 1981a, 1981b) and semantic categorization of pictures (Morrison et al., 1992), have typically failed to find any independent effect of AoA. This has led to the suggestion that the locus of the AoA effect is at the retrieval of lexical phonology (Gilhooly \& Watson, 1981). However, a notable exception to this general claim comes from the finding that AoA, as well as frequency, affects performance in the lexical decision task (Morrison \& Ellis, 1995; Turner et al., 1998), which does not require overt naming. In the present study, therefore, we addressed two major theoretical questions: (1) What are the joint effects of word frequency and AoA in the lexical decision task (LDT)? (2) Are the effects of AoA in the LDT dependent upon the retrieval of phonology?

\section{Effects of Frequency and AoA in the LDT}

In many studies, researchers have reported an effect of word frequency in the LDT, but results concerning AoA have been less clear cut. Using a multiple regression design, Gilhooly and Logie (1982) found that word frequency was the main predictor of lexical decision latency, but AoA did not reach significance. However, others have found evidence for the independent effects of both AoA and frequency in the LDT (Butler \& Hains, 1979; Nagy, Anderson, Schommer, Scott, \& Stallman, 1989; Whaley, 1978). Morrison and Ellis (1995), using a semifactorial design, found effects of both frequency (when words were matched for AoA) and AoA (when words were matched for frequency). Using a similar design, Turner et al. (1998) also found that both frequency and $A o A$ affected visual lexical decision times, whereas AoA, but not frequency, affected auditory lexical decision 
times. Morrison and Ellis suggested that the lack of an AoA effect in the Gilhooly and Logie (1982) study was due to its being suppressed by its correlation with other variables. This view had previously been expressed by Morris (1981). The problem comes about because the difficulty of attempting to match words on several variables often leads to smaller sample sizes than would be ideal; consequently, in most studies, large sets of words have been used, and multiple regression has been employed in the attempt to partial out the influence of associated variables. We are aware of only one attempt to examine the effects of frequency and AoA that used a fully factorial design in the LDT; this is an unpublished study by Linda Cupples (reported by Forster, 1992), who found that both variables exerted a significant effect and that they also interacted, with the AoA effect being stronger for low-frequency words. However, it would appear that Cupples did not control for concreteness, which has been shown to influence lexical decision times in several studies (e.g., in Kroll \& Merves, 1986; Schwanenflugel \& Shoben, 1983; and Whaley, 1978). Our first major aim in the studies reported here was, therefore, to determine the respective roles of word frequency and AoA in the LDT. Given the extensive use of the LDT in studies of lexical processing, whether AoA or frequency (or, indeed, both variables) needs to be controlled is a major empirical question. Furthermore, it is theoretically important to determine whether the variables interact. In particular, if current theories are correct in suggesting that AoA affects the retrieval of phonology and low-frequency words are more dependent on such phonological processing in the LDT, then AoA should interact with frequency. In previous studies of AoA effects in the LDT, researchers have not been able to look for interactions between AoA and frequency, since they have generally used multiple regression designs (see, e.g., Gilhooly \& Logie, 1982) or semifactorial designs (e.g., Morrison \& Ellis, 1995). In the experiment reported here, we used a fully factorial (or $2 \times 2$ ) design, in which we manipulated AoA and frequency orthogonally and in which we matched the words in each condition on other important dimensions (such as concreteness) that affect latencies in the LDT.

\section{Are Effects of AoA in the LDT Dependent on the Retrieval of Phonology?}

An important theoretical issue concerns the stage of processing at which the variables of AoA and frequency exert their influence. Morton's $(1969,1979)$ influential logogen model placed the frequency effect at the level of word recognition. In this model, each word is represented by its own detection unit, or logogen, which fires once the level of activation reaches a certain threshold. Successive encounters with a word progressively lower the threshold of its logogen so that words encountered more frequently come to be recognized more rapidly. Similarly, in McClelland and Rumelhart's (1981) connectionist model, each familiar word has its own node, with a resting level of activation determined over a period of time by the word's frequency of occurrence. The resting activation levels of the nodes of high-frequency words are higher than those of low-frequency words, because of the greater positive activation that they have received from the repeated presentations of high-frequency words. In support of the notion that frequency affects word recognition, studies of eye fixations during the reading of text have shown longer pauses on low-frequency than on highfrequency words (Inhoff \& Rayner, 1986; Just \& Carpenter, 1980). Also, Gilhooly and Logie (1981b) showed that frequency affects the visual recognition threshold of words presented tachistoscopically.

However, there are also suggestions that frequencysensitive mechanisms operate at stages of processing after lexical access has occurred (i.e., after words have been recognized). The original explanation of performance in the LDT was that a serial search of the lexicon was engaged in until a match between the incoming sensory information and a stored representation was detected (Rubenstein, Lewis, \& Rubenstein, 1971). This explanation was further developed to include the idea that the search is limited to particular groups of lexical entries, which are selected, on the basis of sensory characteristics, prior to the commencement of the search (Forster, 1976; Forster \& Bednall, 1976). It was proposed that such entries are organized in terms of their frequency of occurrence, so that entries for high-frequency words would be accessed more rapidly than those for low-frequency words. This interpretation was challenged by Balota and Chumbley (1984), who reasoned that if frequency affects lexical access directly, any task that necessitates lexical access should also show a frequency effect. Their own lexical decision data were highly frequency sensitive, but they found a frequency effect only for positive responses in a category-verification task. They explained these results in terms of a two-stage model developed by Atkinson and Juola (1973), in which word/nonword discriminations are performed on the basis of the familiarity or meaningfulness of the letter strings. Balota and Chumbley (1985) also proposed a postaccess, familiarity-based decision process to explain why they found apparent frequency effects in a delayed naming task, although Monsell et al. (1989) suggested that this was because participants reprocessed the words before naming them. In two studies, McCann and Besner (1987) found that naming latencies to pseudohomophone nonwords (such as burd) were not related to the frequency of the words to which they sounded identical (bird), although a frequency effect was found when participants were required to say whether or not a nonword sounded like a real word (McCann, Besner, \& Davelaar, 1988). The explanation was that the frequency effect resulted from a familiarity-based decision process, which occurred postlexically and was reasoned to be required for homophone and lexical decisions, but not for naming. According to Balota and Chumbley (1984), lexical decisions to high-frequency words and nonwords are made on the basis of a familiarity-based decision, whereas low-frequency words require extra in- 
formation gained through the more time-consuming process of lexical checking. Therefore, even within this type of interpretation, frequency is still assumed to play a role.

AoA seems to exert its influence at a later stage of processing. Gilhooly and Logie (1981a, 1981b) found no evidence for an AoA effect on visual or auditory word recognition thresholds, which suggests that observed AoA effects in naming and lexical decision must result from processes operating after lexical access. Morrison et al. (1992) found that AoA affected picture naming latencies, but not performance on a living versus a nonliving categorization task on the same pictures, which suggests that the AoA effect in naming arises from postsemantic processes. The most likely locus of the AoA effect is, therefore, at the stage of retrieval of lexical phonology. This proposal is supported by the finding that AoA exerts an influence on speech rate (Gerhand \& Barry, 1998; Roodenrys, Hulme, Alban, Ellis, \& Brown, 1994) and the general finding that effects are most robust in tasks that involve overt naming (Gilhooly \& Watson, 1981).

Currently, the most popular explanation of the AoA effect in picture and word naming is the phonological completeness hypothesis advanced by Brown and Watson (1987). This hypothesis proposes that the phonological forms of early-acquired words are stored in a relatively complete form in the speech output lexicon, whereas lateacquired words are stored in a more fragmentary fashion (and, indeed, may be structured around the more complete forms of early-acquired words). It is assumed that the phonology of late-acquired words needs to be assembled for pronunciation, so that it takes longer to read aloud lateacquired words than early-acquired words.

If it is the case that AoA affects retrieval of phonology, what pattern would be expected in the LDT? It is incontestable that, if all the nonwords used in the task are orthographically legal (and so are pronounceable), successful performance in the LDT requires that words gain access to their lexical representations. However, it is now considered unlikely that the task taps only the processes necessary for lexical access; indeed, there exists considerable evidence to suggest that performance in the task is influenced by both semantic variables, such as concreteness (see, e.g., Kroll \& Merves, 1986), and phonological variables (e.g., Besner \& Davelaar, 1983; Cotheart, Davelaar, Jonasson, \& Besner, 1977; Davelaar, Coltheart, Besner, \& Jonasson, 1978; Rubenstein et al., 1971; Seidenberg, Petersen, MacDonald, \& Plaut, 1996). Coltheart et al. (1977) proposed the dual-route model of reading, wherein a written word is processed in two possible ways: by a direct (or visual) route, which matches the visual input to an orthographic lexical entry, or by a slower phonologically mediated route. If one accepts the logic that low-frequency words are more often processed via the phonological route-and that AoA affects the retrieval of phonology-then it is to be expected that the AoA would have a greater effect for low- than for high-frequency words.
In this article, we report the results of five experiments on the respective roles of AoA and word frequency in the LDT. The designs were fully factorial, with these two variables manipulated orthogonally. This approach enabled us, within each experiment, to examine the relative effects of AoA and frequency and, more importantly, to determine whether the two effects interact. In Experiment 1 , we used a standard LDT (in which the nonwords were orthographically legal and pronounceable) in order to address our first major aim-namely, to establish the joint effects of word frequency and AoA in the LDT. The other four experiments were attempts to manipulate the use of phonological processing in various ways in order to address our second major aim-namely, to determine whether the effects of AoA in the LDT are dependent on the retrieval of phonology.

\section{EXPERIMENT 1}

\section{Method}

Participants. Thirty undergraduate and postgraduate psychology students (23 female, 7 male) at Cardiff University participated in the experiment. All spoke English as their first language, and all could read fluently, with either unaided or corrected vision. Participation was in exchange for course credit or $£ 2.50$ (\$4).

Design. Sixty-four words were chosen, with 16 in each of the following four conditions: (1) early-acquired, high-frequency (e.g., men, people); (2) early-acquired, low-frequency (e.g., pet, rhyme); (3) late-acquired, high-frequency (e.g., tax, moral); and (4) lateacquired, low-frequency (e.g., urn, rogue). Early-acquired words had AoA values (taken from Gilhooly \& Logie, 1980) of less than 3.00 (estimated as being acquired at 5-6 years of age or younger), and the late-acquired words had AoA values of 5.00 or above (acquired at $9-10$ years of age or older). Gilhooly and Logie (1980) obtained AoA ratings by requiring participants to estimate at what age they first learned each word, using a 7-point scale (where a rating of 1 was to given to words acquired between the ages of 0 and 2 years, and a rating of 7 was given to words acquired at age 13 and older). Several studies have shown that these ratings correlate impressively highly with objective measures of the age at which words are actually learned, thus validating their use (e.g., Carroll \& White, 1973; Gilhooly \& Gilhooly, 1980; Lyons, Teer, \& Rubenstein, 1978; Morrison, Chappell, \& Ellis, 1997). High-frequency words were chosen as having a frequency count (from Kučera \& Francis, 1967) of at least 50 occurrences per million, and low-frequency words had a frequency count of fewer than 5 per million. The words in each category were matched for their rated concreteness (and imageability) values, as provided by Gilhooly and Logie (1980), and word length (in terms of number of letters). Full details of the experimental words are in Table 1, and the full list of words used is in the Appendix. In order to ensure that, in selecting the words of high and low frequencies from one count (Kučera \& Francis, 1967), there was no tendency toward regression to the mean, we also examined the frequency counts of our words in the study of word frequencies in British English provided by Hofland and Johansson (1982). The mean frequencies of the words in this study are also in Table 1; we can be sure that our high- and low-frequency words are indeed distinct.

Additionally, 64 nonwords were created by using real words of the same length as each of the stimulus words' and altering one or more letters. All nonwords were pronounceable, and none were homophonic to real words. Examples of the nonwords used are: elt, hish, condim, and fashmoone. Practice stimuli, also taken from Gilhooly and Logie (1980), were made up of 20 medium-frequency 
Table 1

Characteristics of the Stimuli Used

\begin{tabular}{|c|c|c|c|c|c|c|c|c|c|}
\hline \multirow[b]{2}{*}{ Stimuli } & \multicolumn{2}{|c|}{ KF Freq. } & \multicolumn{2}{|c|}{ HJ Freq. } & \multicolumn{2}{|c|}{ AOA } & \multirow[b]{2}{*}{ Con. } & \multirow[b]{2}{*}{ Imag. } & \multirow[b]{2}{*}{ Length } \\
\hline & $M$ & Range & $M$ & Range & $M$ & Range & & & \\
\hline Early, high-frequency (e.g., cousin) & 206.3 & $51-847$ & 197.9 & $19-953$ & 2.67 & $2.19-2.92$ & 5.05 & 5.25 & 5.6 \\
\hline Early, low-frequency (e.g., rattle) & 4.2 & $0-9$ & 4.6 & $0-17$ & 2.71 & $2.19-2.97$ & 4.92 & 5.35 & 5.6 \\
\hline Late, high-frequency (e.g., union) & 146.2 & $57-382$ & 121.1 & $40-206$ & 4.82 & $4.50-5.39$ & 4.52 & 4.95 & 5.9 \\
\hline Late, low-frequency (e.g., marvel) & 3.3 & $0-9$ & 2.6 & $0-13$ & 4.91 & $4.42-5.52$ & 5.03 & 5.14 & 5.6 \\
\hline
\end{tabular}

Note-For each condition, we give the mean value (and, for some, the range of values) for the following variables: Kučera and Francis (1967) word frequency (KF Freq.), Hofland and Johansson (1982) word frequency (HJ Freq.), Gilhooly and Logie (1980) age of acquisition (AOA), concreteness (Con.) and imageability ratings (Imag.), and word length in number of letters.

words (with counts between 10 and 50 per million) of medium AoA (with ratings between 3 and 4.5).

Procedure. Stimuli were presented sequentially on the screen of a Macintosh LC computer in black lowercase 18-point Geneva font. The order of presentation was randomized (with words and nonwords randomly interspersed) separately for each participant. The LDT was performed by pressing the "/" key on a keyboard with the index finger of the right hand in response to a real word, and by pressing the " $z$ " key with the index finger of the left hand in response to a nonword. This response pattern was reversed, if requested, for left-handed participants. There was an intertrial interval of $1 \mathrm{sec}$ between each response and presentation of the next stimulus. Reaction times for all responses were recorded by the computer in milliseconds. Prior to the main experiment, participants responded to 40 practice items ( 20 words and 20 nonwords, such as sunge and obulent).

\section{Results}

Harmonic means of the latencies of correct responses were calculated for each condition for each participant and for each word. We calculated these rather than arithmetic means (or medians, or means after variously defined outliers had been excluded), because harmonic means involve a reciprocal transformation of the data and so reduce the skew of latency distributions toward slower responses. This is also a method that Ratcliff (1993) recommends as being suitable for use with analysis of variance (ANOVA). The arithmetic means of the harmonic means of naming times in each condition for Experiment 1 are shown in Table 2. Error rates to words were very low (at only $1.2 \%$ overall). The mean for responses to nonwords was $705 \mathrm{msec}(S D=218.6)$, with $7.4 \%$ errors.

Two two-factor ANOVAs were performed on the responses to words, one by participants (in which the two variables of $\mathrm{AoA}$ and frequency were within-subjects factors) and one by words (in which the two variables were between-item factors). Unless otherwise stated, a significance level of $p<.01$ was adopted. The main effects of both AoA and frequency were significant in both analyses: There was a 59-msec effect of AoA $\left[F_{\mathrm{s}}(1,29)=22.88\right.$, $\left.M S_{\mathrm{e}}=4,645.13 ; F_{\mathrm{i}}(1,60)=20.57, M S_{\mathrm{e}}=4,262.44\right]$ and a 77 -msec effect of frequency $\left[F_{\mathrm{s}}(1,29)=35.22, M S_{\mathrm{e}}=\right.$ $\left.5,105.71 ; F_{\mathrm{i}}(1,60)=37.66, M S_{\mathrm{e}}=4,262.44\right]$. The interaction between the two variables was also significant $\left[F_{\mathrm{s}}(1,29)=12.76, M S_{\mathrm{e}}=5,833.06 ; F_{\mathrm{i}}(1,60)=16.24\right.$, $\left.M S_{\mathrm{e}}=4,262.44\right]$. As can be seen in Table 2, the effect of AoA was greater for the low-frequency $(109 \mathrm{msec})$ than for the high-frequency words $(10 \mathrm{msec})$. An analysis of the simple effects of AoA showed that the effect was significant for low-frequency words $\left[F_{\mathrm{s}}(1,29)=19.77, M S_{\mathrm{e}}=\right.$ $\left.9,068.56 ; F_{\mathrm{i}}(1,60)=48.43, M S_{\mathrm{e}}=1,689.28\right]$, but did not reach significance for high-frequency words $\left[F_{\mathrm{s}}=1.0\right.$; $\left.F_{\mathrm{i}}=1.18\right]$.

\section{Discussion}

Experiment 1 revealed an influence of both frequency and AoA on latencies in the LDT. The substantial AoA

Table 2

Results of Experiments 1-5: Mean (Correct) Lexical Decision Latencies (in Milliseconds) and Percentage Error Rates in Each Condition, Along With the Magnitudes of the Age of Acquisition Effects (Late Minus Early) and of the Interactions

\begin{tabular}{|c|c|c|c|c|c|c|c|c|c|c|c|}
\hline \multirow[b]{3}{*}{ Experiment } & \multicolumn{5}{|c|}{ High-Frequency Words } & \multicolumn{5}{|c|}{ Low-Frequency Words } & \multirow[b]{3}{*}{ Interaction } \\
\hline & \multicolumn{2}{|c|}{ Early } & \multicolumn{2}{|c|}{ Late } & \multirow[b]{2}{*}{ AoA Effect } & \multicolumn{2}{|c|}{ Early } & \multicolumn{2}{|c|}{ Late } & \multirow[b]{2}{*}{ AoA Effect } & \\
\hline & $M$ & $\% \mathrm{E}$ & $M$ & $\% \mathrm{E}$ & & $M$ & $\% \mathrm{E}$ & $M$ & $\% \mathrm{E}$ & & \\
\hline 1 & 593 & 0.5 & 603 & 0.5 & 10 & 621 & 0.2 & 730 & 3.4 & 109 & 99 \\
\hline 2 & 489 & 0.2 & 494 & 0.3 & 5 & 503 & 0.5 & 547 & 2.0 & 44 & 39 \\
\hline 3 & 620 & 0.2 & 653 & 0.5 & 33 & 687 & 1.6 & 766 & 3.8 & 79 & 46 \\
\hline 4 & 577 & 0.1 & 599 & 0.5 & 22 & 618 & 1.1 & 673 & 3.9 & 55 & 33 \\
\hline 5 & 597 & 0.3 & 617 & 0.9 & 20 & 634 & 1.3 & 711 & 4.7 & 77 & 57 \\
\hline
\end{tabular}

Note-Experiment 1 used pronounceable, legal nonwords; Experiment 2 used orthographically illegal nonwords; Experiment 3 used pseudohomophone nonwords; Experiment 4 used nursery rhyme articulatory suppression; and Experiment 5 used repetition of "the the the" as articulatory suppression. 
effect is, perhaps, a little surprising in the light of previous studies that indicated a tendency toward the strongest AoA effects' being found in naming tasks; it is consistent, however, with the idea that retrieval of phonology occurs during the LDT. The interaction between AoA and frequency is particularly interesting, because this is the same pattern found in the study by Cupples that was reported in Forster (1992). However, unlike the results of that particular study, our results cannot be due to any confounding effects of concreteness, imageability, or length, since we matched for these variables in our choice of stimuli. Also, the interaction cannot be explained away by the presence of unequal numbers of irregular words in the four conditions, for two reasons. First, there was no systematic difference between the conditions in the very few irregular words that were present. Second, because spelling-to-sound regularity has been demonstrated to interact with word frequency in naming (Seidenberg, Waters, Barnes, \& Tanenhaus, 1984), it might be argued that the presence of even one or two irregular words in a lowfrequency condition might slow down the mean decision latency for that condition. However, this is unlikely to be the case, because the advantage for regularly spelled words seen in naming tasks does not always extend to the LDT (see, e.g., Andrews, 1982; Coltheart, Besner, Jonasson, \& Davelaar, 1979; Coltheart et al., 1977; Mason, 1978; Parkin, 1982, 1984; Seidenberg et al., 1984). The question that must now be addressed is how the observed interaction between $\mathrm{AoA}$ and frequency arose. If the locus of the AoA effect is the retrieval of phonology, then manipulations intended to interfere with phonological processing should remove or reduce the AoA effect. This was tested in the following four experiments.

\section{EXPERIMENTS 2-5}

A possible role for AoA in the LDT might be at a postlexical verification stage, when a response is made only after accessing the phonological characteristics of the word. This could explain the interaction observed between AoA and frequency, with the effects of AoA being reliable for only low-frequency words. For common words, a decision may be possible largely on the basis of visual characteristics; however, less common words may require an extensive phonological checking procedure. A similar explanation might be made on the basis of Coltheart's (1978) dual-route model-namely, that a decision based purely on accessing the lexicon might be possible for common words, but, for low-frequency words, for which lexical access is less rapid, decisions are made on the basis of assembled phonological recoding. We shall return to this idea in the General Discussion. In the following four experiments, we addressed this issue by attempting to manipulate the contribution of phonological processing in the LDT.

In Experiment 2, we used orthographically illegal nonwords to facilitate a response based on visual characteristics. If all the nonwords used in a LDT are orthograph- ically illegal (and thus unpronounceable), reliance on phonological characteristics should be expected to be reduced, because it should be possible to base the responses to words purely on their familiar visual characteristics. This should remove the influence of AoA, but leave an effect of frequency. Also, if retrieval of phonology is no longer necessary to make a decision to low-frequency words, the interaction between AoA and frequency should also be removed or reduced.

In Experiment 3, we used only pseudohomophones as nonwords. If all the nonwords in a LDT sound identical to real words, the use of assembled (or sublexical) phonological recoding will generate representations that will, confusingly, match those of real words. Thus, the use of pseudohomophones should encourage participants to abandon reliance on assembled phonology (Davelaar et al., 1978). Furthermore, if the AoA effect observed in Experiment 1 was due to the use of assembled phonology, its effect should be diminished by the use of pseudohomophones.

In Experiments 4 and 5, we used the secondary task of concurrent articulatory suppression to try to make retrieval of phonology as difficult as possible. Studies showing the detrimental effect of continuously articulating a single word while trying to retain a verbal list in short-term memory have led to the suggestion that articulatory suppression prevents the generation of a phonological code from visual input (see, e.g., Baddeley, Thomson, \& Buchanan, 1975; Coltheart, Avons, \& Trollope, 1990). Although articulatory suppression interferes with the ability to make rhyme judgments (see, e.g., Baron \& Baron, 1977; Johnston \& McDermott, 1986; Kleiman, 1975), it does not impair the ability to carry out various forms of homophone decision (Baddeley \& Lewis, 1981; Besner, Davies, \& Daniels, 1981; Howard \& Franklin, 1989). This suggests that, although articulating a single word repeatedly may interfere with the maintenance of a phonological code, it does not prevent the generation of a code from the phonological output lexicon. To ensure that articulatory suppression interfered with the retrieval of lexical phonology, in Experiment 4 we used the task of reciting a well-rehearsed nursery rhyme ${ }^{1}$, a task that should require the participant to constantly retrieve items from the phonological output lexicon (but, in a way that we hoped would not place too much demand on general cognitive resources, such as semantic processing). In Experiment 5, we used the more conventional form of articulatory suppression that required simply repeating the single word the.

In summary, we used different means to achieve the common goal of minimizing phonological processing in the LDT. If AoA effects are due to phonological processing, the effect of AoA and its interaction with frequency should be reduced or eliminated in Experiments 2-5.

\section{Method}

Participants. Thirty different undergraduate and postgraduate psychology students at Cardiff University participated in each experiment. All spoke English as their first language and had normal 
or corrected-to-normal vision. Participation was in exchange for course credit, and no one participated in more than one experiment.

Stimulus materials. In all the experiments we used the same 64 words as in Experiment 1. In Experiment 2, we replaced the original nonwords with 64 orthographically illegal nonwords, which we created by using words of the same length as each of the experimental words (though not the words themselves) and replacing vowels with consonants so as to make them unpronounceable; examples of these nonwords are wrsl, grwtp, and fhrunce. In Experiment 3, we used pseudohomophones as nonwords, which we constructed from words of a length similar to that of those used in the experiment although none were actually homophonic with the experimental words; examples of the pseudohomophones used are dore, fackter, and aboad. In Experiments 4 and 5, we used the same orthographically legal (but nonhomophonic) nonwords as in Experiment 1 .

Procedure. In all experiments, the participants were seated in front of a Macintosh IIvi computer, at a distance of $30 \mathrm{~cm}$. The stimuli were presented in black, bold, lowercase 18-point Geneva font (on a white screen) in a random order, with 20 practice trials first. The participants responded by pressing the "/" key in response to a real word and the " $\mathrm{z}$ " key in response to a nonword; this pattern was reversed upon request for left-handed participants. Response latency was measured by the program as the delay between presentation of the stimuli and making the response. Experiments 2 and 3 were preceded by 20 practice trials.

In Experiment 4, the word Ready? appeared on the computer screen between each stimulus item, and the participants were asked to continually recite "Mary had a little lamb, its fleece was white as snow, and everywhere that Mary went, that lamb was sure to go"; the nursery rhyme was requested to be recited as a whole, without pause. At some point during the recitation of this rhyme, the experimenter triggered the presentation of each stimulus in a manner unseen by the participant. Presentation of the stimulus varied from trial to trial, so that the participants were not able to predict when presentation would occur. Sometimes no stimulus was presented during the course of the rhyme, and sometimes more than one was presented. The participants had to respond to each item while still articulating the rhyme without pause. Forty practice trials were given, because pilot work indicated that the participants would find this task difficult to perform.

In Experiment 5, the procedure was identical to that of Experiment 4 , with the exception that the participants were required to repeat the single word the continually. The experimental trials were preceded by 40 practice trials.

\section{Results}

Arithmetic means of the harmonic mean correct responses to words in each condition for each experiment are shown in Table 2. The mean of correct responses to the nonwords used in each experiment were as follows: Experiment 2 (illegal nonwords), $478 \mathrm{msec}(S D=125.6)$ with $0.9 \%$ errors; Experiment 3 (pseudohomophone nonwords), $828 \mathrm{msec}(S D=259.4)$ with $6.8 \%$ errors (which shows that the pseudohomophones were indeed harder to process); Experiment 4 (legal nonwords), $646 \mathrm{msec}$ $(S D=137.8)$ with $9.5 \%$ errors; and Experiment 5 (legal nonwords), $755 \mathrm{msec}(S D=302.9)$ with $2.2 \%$ errors.

The data for correct responses to words were analyzed in three-way ANOVAs, both by subjects and by items. These contained the variables of experiment, AoA, and frequency. In the analysis by subjects, experiment was a between-subjects factor, and AoA and frequency were within-subjects factors, whereas in the analysis by items, experiment was a within-item factor and AoA and frequency were between-item factors. There was a significant effect of experiment $\left[F_{\mathrm{s}}(3,116)=22.00, M S_{\mathrm{e}}=\right.$ $\left.29,865.45 ; F_{\mathrm{i}}(3,180)=391.03, M S_{\mathrm{e}}=778.98\right]$. Post hoc Tukey tests indicated that the responses in Experiment 2 (with illegal nonwords) were significantly faster than those in the other experiments. The difference between Experiment 3 (pseudohomophones) and Experiment 4 (concurrent articulation of a nursery rhyme) was also significant at the $p<.05$ level. There were significant main effects of frequency $\left[F_{\mathrm{s}}(1,116)=197.51, M S_{\mathrm{e}}=2,340.49\right.$; $\left.F_{\mathrm{i}}(1,60)=66.12, M S_{\mathrm{e}}=3,765.82\right]$ and AoA $\left[F_{\mathrm{s}}(1,116)=\right.$ $\left.232.31, M S_{\mathrm{e}}=890.32 ; F_{\mathrm{i}}(1,60)=33.49, M S_{\mathrm{e}}=3,765.82\right]$ and also a significant interaction between these variables $\left[F_{\mathrm{s}}(1,116)=39.31, M S_{\mathrm{e}}=1,436.23 ; F_{\mathrm{i}}(1,60)=10.48\right.$, $M S_{\mathrm{e}}=3,765.82$. Analyses of simple main effects showed a larger AoA effect for low-frequency words $\left[F_{s}(1,232)=\right.$ 206.07, $M S_{\mathrm{e}}=1,163.28 ; F_{\mathrm{i}}(1,60)=40.29, M S_{\mathrm{e}}=$ $3,765.82]$ than for high-frequency words $\left[F_{s}(1,232)=\right.$ $20.27, M S_{\mathrm{e}}=1,163.28 ; F_{\mathrm{i}}(1,60)=3.37, M S_{\mathrm{e}}=3,765.82$, $p=.07]$. Although AoA interacted with experiment $\left[F_{\mathrm{s}}(3,116)=5.70, M S_{\mathrm{e}}=890.32 ; F_{\mathrm{i}}(3,180)=3.94, M S_{\mathrm{e}}=\right.$ 778.98], analyses of simple effects showed that the AoA effect was reliable for each experiment $\left[F_{s}(1,116) \geq 21.09\right.$, $\left.M S_{\mathrm{e}}=890.32 ; F_{\mathrm{i}}(1,240) \geq 8.33, M S_{\mathrm{e}}=1,525.69\right]$. Frequency also interacted with experiment $\left[F_{\mathrm{s}}(3,116)=7.13\right.$, $\left.M S_{\mathrm{e}}=2,340.50 ; F_{\mathrm{i}}(3,180)=10.48, M S_{\mathrm{e}}=778.98\right]$, but analyses of simple effects showed that the frequency effect was significant for each experiment $\left[F_{\mathrm{s}}(1,116) \geq 13.59\right.$, $\left.M S_{\mathrm{e}}=2,340.50 ; F_{\mathrm{i}}(1,240) \geq 8.33, M S_{\mathrm{e}}=1,525.69\right]$. The three-way interaction of experiment, AoA, and frequency was absent $\left[F_{\mathrm{s}}<1 ; F_{\mathrm{i}}<1\right]$.

To examine the impact of the manipulations used in Experiments $2-5$ on the AoA effect and the interaction between $\mathrm{AoA}$ and frequency, additional analyses were performed by comparing the results of Experiment 1 and those of Experiments 2-5 (taken as a single group). These ANOVAs contained the factors of experiment (Experiment 1 vs. Experiments 2-5 collapsed together), AoA, and frequency. In addition to the main effects of AoA and frequency, and the interaction between the two, both of which have been reported above, there was an interaction between experiment and AoA, which was significant by subjects $\left[F_{\mathrm{s}}(1,148)=4.55, M S_{\mathrm{e}}=1,710.80, p=\right.$ $.04]$ and almost significant by items $\left[F_{\mathrm{i}}(1,60)=3.73\right.$, $M S_{\mathrm{e}}=424.88, p=.06$ ], although analyses of simple effects showed that the AoA effect was reliable for both Experiment $1\left[F_{\mathrm{s}}(1,148)=31.06, M S_{\mathrm{e}}=1,710.80\right.$; $\left.F_{\mathrm{i}}(1,60)=32.34, M S_{\mathrm{e}}=1,689.28\right]$ and Experiments $2-5$ $\left[F_{\mathrm{s}}(1,148)=60.45, M S_{\mathrm{e}}=1,710.80 ; F_{\mathrm{i}}(1,60)=33.40\right.$, $\left.M S_{\mathrm{e}}=943.35\right]$. The three-way interaction of experiment, AoA, and frequency was also significant $\left[F_{\mathrm{s}}(1,148)=\right.$ $\left.8.32, M S_{\mathrm{e}}=2,280.90 ; F_{\mathrm{i}}(1,60)=6.31, M S_{\mathrm{e}}=424.88\right]$, which showed that, as predicted, the factor of experiment 
had a reliable effect on only the late-acquired, lowfrequency words.

\section{GENERAL DISCUSSION}

The pattern of results found across the five experiments can be summarized easily as follows. In the "standard" lexical decision task, with orthographically legal but nonhomophonic nonwords, performed without any secondary task, clear and sizeable effects of both AoA and frequency were found. Also, these variables interacted in such a way that the AoA effect was reliable for only lowfrequency words. This interaction was interpreted in terms of frequency affecting lexical access and AoA affecting a postaccess decision, or checking, stage (of the kind proposed by Balota \& Chumbley, 1984, 1985), in which phonological representations are consulted in order to make confident lexical decisions, particularly for lowfrequency words. We propose that AoA affects the ease with which phonological information becomes available in this process in such a way that the phonology of lateacquired words is slower to be activated, and thus lexical decisions will be made more slowly to late-acquired than to early-acquired, low-frequency words. This conclusion is supported by our findings that each of the manipulations used in Experiments 2-5, which were designed to interfere with (and so reduce the role of) phonological information in the LDT, reduced the magnitude of the AoA effects, particularly for low-frequency words.

\section{The Mechanism Underlying the Interaction Between AoA and Frequency}

So far, we have assumed that word frequency affects the speed with which visual lexical access is carried out and that AoA affects the retrieval of lexical phonology. What specifically does this mean in terms of how the LDT is performed? As mentioned earlier, it seems unlikely that the LDT can be seen as a pure measure of orthographic word recognition. The viewpoint that we favor (see also McRae, Jared, \& Seidenberg, 1990; Monsell, 1991 ) is that both orthographic and phonological (and perhaps also semantic) information is activated in the task, in a cascading fashion. Information from all these different domains of processing is pooled together, and a decision is made when a particular criterion level of lexical activity is reached. An interpretation of the interaction found between AoA and frequency that is consistent with this framework is that positive lexical decisions could be made whenever the activation of either the orthographic or the phonological lexical representation reaches a threshold level (see also Grainger \& Ferrand, 1994). Typically, orthographic activation will reach threshold first, because activating the phonological representation requires further processing. Our interpretation of the interaction between AoA and frequency is that the orthographic representations of high-frequency words will be activated most rapidly, so that responses to these words in the LDT will normally be made before the activation of phonological representations have reached threshold; for these words, no effect of AoA should be apparent. However, the orthographic representations of low-frequency words will take longer to attain the critical level of activation, and, therefore, positive responses to these words are more likely to be made on the basis of the activation of the phonological representations reaching threshold. We assume that the phonological representations of early-acquired words will be accessed more rapidly than those of late-acquired words (because of their greater phonological "completeness"); hence, a larger AoA effect will be found for low- than for highfrequency words, which is the pattern observed. If one assumes that processing occurs in cascade, which most models of word naming currently favor (e.g., Coltheart, Curtis, Atkins, \& Haller, 1993; Seidenberg \& McClelland, 1989), it does not matter whether the initial activation of an orthographic representation occurs first, as long as activated phonological representations reach threshold first.

One possible objection to this interpretation is that responses to low-frequency words in Experiment 2 were actually faster than those to high-frequency words in the other experiments, and yet an AoA effect was still apparent. ${ }^{2}$ If high-frequency words do not show AoA effects because their orthographic representations are accessed before phonological information is activated, one might expect that the AoA effect would disappear for lowfrequency words when responses to these words are very fast. It was certainly true that the use of illegal nonwords in Experiment 2 resulted in overall faster responses. However, we would stress that these illegal nonwords were unpronounceable, and so would not give rise to any phonological representation. A lexical decision under these conditions could therefore be made purely on the basis of whether or not any phonology was generated; hence, a less cautious response criterion could be adopted, in which a lower level of activation would be required before a decision was made, but in which early-acquired words would still lead to the activation of stored phonology before late-acquired words.

Morrison and Ellis (1995) suggested that the AoA effects in the LDT arise from the use of lexically derived phonology as part of the decision-making process. Our data are also consistent with such an interpretation. Previous interpretations of performance in the LDT have suggested that the decision process might be based on the familiarity of words (Balota \& Chumbley, 1985; Gernsbacher, 1984). Familiarity correlates very highly with AoA; Gilhooly and Logie (1980) found that rated word familiarity correlates -.72 with rated AoA (earlyacquired words are rated to be more familiar). Brown and Watson (1987) suggested that people may actually base their subjective ratings of familiarity on how easily they can access the phonological characteristics of words. It may, therefore, be possible that previous studies showing 
effects of familiarity in the LDT have been confounded with effects due to AoA.

\section{Why Was the AoA Effect \\ Not Eliminated in Experiments 2-5?}

In general, the main effect of the present manipulations was to speed up responses to low-frequency, lateacquired words - that is, those for which identification would be most dependent on phonological characteristics (Seidenberg et al., 1984) and for which the phonological form would take longest to retrieve (Gilhooly \& Watson, 1981). However, a question remains: Why did none of our manipulations remove the AoA effect completely? The most probable reason is that the presentation of a word results automatically (and unavoidably) in some form of phonological processing. This is more consistent with models of reading that place derivation of a phonological representation as the primary process in reading (see, e.g., Lukatela \& Turvey, 1994a, 1994b; Van Orden, 1987, 1991; Van Orden, Johnston, \& Hale, 1988; Van Orden, Pennington, \& Stone, 1990). These phonological mediation models propose that on an initial encounter with a printed letter string, a prelexical phonological code is created, and that this is compared with representations within a phonological lexicon. If there is a match, the activation of the semantics of that lexical entry occurs (e.g., both GRATE and GRAIT would activate the semantics of great), and its corresponding spelling is retrieved, which can then be matched against the orthographic input. The fact that responses to pseudohomophones in Experiment 3 were slow and were associated with a relatively high error rate suggests that this manipulation did not eliminate phonological processing. An AoA effect could be incorporated within this framework at the stage of comparing the prelexical phonological codes with the stored lexical phonological representations. If one assumes that the phonological representations of earlyacquired words are easier to activate than those of lateacquired words, the matching process would take place more rapidly for the former than for the latter. There is also a "weaker" version of the phonological mediation hypothesis, which allows for parallel activation of prelexical and addressed phonology (Frost, 1995). Although the studies reported in this article were not designed to evaluate this hypothesis directly, we are inclined to think that our results are best explained by the automatic and compulsory activation of phonology in word recognition (and certainly in the LDT). This also fits with views of modularity (see Fodor, 1983), such as the one proposed by Moscovitch and Umiltà (1990), in which reading is subserved by Type III, or experientially assembled, modules. These consist of integrated assemblies of simpler processors, which come to function in a modular fashion as a result of practice. Normally, reading a word involves accessing its phonological characteristics, and this will logically occur automatically as people learn to read. Although the LDT does not logically require the accessing of lexical phonology, we suggest that such activation occurs automatically and will be affected by AoA.
There is, of course, an alternative explanation for the pattern of results seen across the five experimentsnamely, that the AoA effect is not localized at the level of phonological processing, but might affect all stages of word processing. Although we cannot rule out this interpretation of all aspects of the results, it seems somewhat premature to embrace such an explanation at present. Currently, there is no firm evidence of AoA effects in any lexical processing task that does not involve the retrieval of phonology. Admittedly, there have been only few attempts to look for possible AoA effects in tasks in which phonological variables have no major influence; for example, Morrison et al. (1992) found no effect of AoA in the semantic categorization of pictures, even when a clear AoA effect on the naming latencies to the same pictures was observed. However, additional studies of the possible effects of $\mathrm{AoA}$ in other lexical processing tasks will be required in order to investigate this further.

\section{REFERENCES}

Allen, P. A., McNeal, M., \& KvaK, D. (1992). Perhaps the lexicon is coded as a function of word frequency. Journal of Memory \& Language, 31, 826-844.

ANDREWs, S. (1982). Phonological recoding: Is the regularity effect consistent? Memory \& Cognition, 10, 565-575.

Atkinson, J. R., \& JUOLA, J. F. (1973). Factors influencing speed and accuracy of word recognition. In S. Kornblum (Ed.), Attention and performance $I V$ (pp. 583-612). New York: Academic Press.

BADDELEY, A. D., \& LEWIS, V. J. (1981). Inner active processes in reading: The inner voice, the inner ear and the inner eye. In A. M. Lesgold \& C. A. Perfetti (Eds.), Interactive processes in reading (pp. 107-129). Hillsdale, NJ: Erlbaum.

Baddeley, A. D., Thomson, N., \& Buchanan, M. (1975). Word length and the structure of short-term memory. Journal of Verbal Learning \& Verbal Behavior, 14, 575-589.

Balota, D. A., \& Chumbley, J. I. (1984). Are lexical decisions a good measure of lexical access? The role of word frequency in the neglected decision stage. Journal of Experimental Psychology: Human Perception \& Performance, 10, 340-357.

Balota, D. A., \& Chumbley, J. I. (1985). The locus of word-frequency effects in the pronunciation task: Lexical access and/or production. Journal of Memory \& Language, 24, 89-106.

BARON, R. W., \& Baron, J. (1977). How children get meaning from printed words. Child Development, 48, 587-594.

Barry, C., Morrison, C. M., \& Ellis, A. W. (1997). Naming the Snodgrass and Vanderwart pictures: Effects of age of acquisition, frequency and name agreement. Quarterly Journal of Experimental Psychology, 50A, 560-585.

BESNER, D., \& DAVELAAR, E. (1983). Seudohomofoan effects in visual word recognition: Evidence for phonological processing. Canadian Journal of Psychology, 37, 300-305.

Besner, D., Davies, J., \& Daniels, S. (1981). Reading for meaning: The effects of concurrent articulation. Quarterly Journal of Experimental Psychology, 33A, 477-491.

Brown, G. D. A., \& WATSON, F. L. (1987). First in, first out: Word learning age and spoken word frequency as predictors of word familiarity and word naming latency. Memory \& Cognition, 15, 208216.

BUTLER, B., \& HAINS, S. (1979). Individual differences in word recognition latency. Memory \& Cognition, 7, 68-76.

Carroll, J. B., \& White, M. N. (1973). Word frequency and age-ofacquisition as determiners of picture naming latency. Quarterly Journal of Experimental Psychology, 12, 85-95.

ColTHEART, M. (1978). Lexical access in simple reading tasks. In $\mathrm{G}$. Underwood (Ed.), Strategies of information processing (pp. 151216). New York: Academic Press.

Coltheart, M., Besner, D., Jonasson, J. T., \& DavelaAr, E. (1979). 
Phonological encoding in the lexical decision task. Quarterly Journal of Experimental Psychology, 31, 489-507.

Coltheart, M., Curtis, B., Atkins, P., \& Haller, M. (1993). Models of reading aloud: Dual route and parallel distributed processing approaches. Psychological Review, 100, 589-608.

Coltheart, M., Davelaar, E., Jonasson, J. T., \& Besner, D. (1977) Access to the internal lexicon. In S. Dornic (Ed.), Attention and performance VI (pp. 535-555). New York: Academic Press.

Coltheart, V., Avons, S. E., \& Trollope, J. (1990). Articulatory suppression and phonological codes in reading for meaning. Quarterly Journal of Experimental Psychology, 42A, 375-399.

DavelaAr, E., Coltheart, M., Besner, D., \& Jonasson, J. T. (1978). Phonological recoding and lexical access. Memory \& Cognition, 6 , 391-402.

FoDOR, J. (1983). The modularity of mind. Cambridge, MA: MIT Press. FORSTER, K. I. (1976). Accessing the mental lexicon. In E. C. G. Walker \& R. J. Wales (Eds.), New approaches to language mechanisms (pp. 257-287). Amsterdam: North-Holland.

FORSTER, K. I. (1992). Memory-addressing mechanisms and lexical access. In R. Frost \& L. Katz (Eds.), Orthography, phonology, morphology, and meaning (Advances in Psychology, Vol. 94, pp. 423435). Amsterdam: North-Holland.

Forster, K. I., \& BedNall, E. S. (1976). Terminating and exhaustive search in lexical access. Memory \& Cognition, 4, 53-61.

Forster, K. I., \& Chambers, S. M. (1973). Lexical access and naming time. Journal of Verbal Learning \& Verbal Behavior, 12, 627-635.

Frederiksen, J. R., \& Kroll, J. F. (1976). Spelling and sound: Approaches to the internal lexicon. Journal of Experimental Psychology: Human Perception \& Performance, 2, 361-379.

FROST, R. (1995). Phonological computation and missing vowels: Mapping lexical involvement in reading. Journal of Experimental Psychology: Learning, Memory, \& Cognition, 21, 398-408.

GERHAND, S., \& BARRY, C. (1998). Word frequency effects in oral reading are not merely age-of-acquisition effects in disguise. Journal of Experimental Psychology: Learning, Memory, \& Cognition, 24, 267283.

GERNSBACHER, M. A. (1984). Resolving 20 years of inconsistent interactions between lexical familiarity, orthography, concreteness, and polysemy. Journal of Experimental Psychology: General, 113, 256 281.

GilHOOLY, K. J., \& GilHoOLY, M. L. (1979). Age-of-acquisition effects in lexical and episodic memory tasks. Memory \& Cognition, 7, 214223.

Gilhooly, K. J., \& GiLhooly, M. L. (1980). The validity of age-ofacquisition ratings. British Journal of Psychology, 71, 105-110.

GiLHOOLY, K. J., \& LOGIE, R. H. (1980). Age-of-acquisition, imagery, concreteness, familiarity, and ambiguity measures for 1,944 words. Behavior Research Methods \& Instrumentation, 12, 395-427.

Gilhooly, K. J., \& LoGIE, R. H. (1981a). Word age-of-acquisition, reading latencies and auditory recognition. Current Psychological Research, 1, 251-262.

GILHOOLY, K. J., \& LOGIE, R. H. (1981b). Word age-of-acquisition and visual recognition thresholds. Current Psychological Research, 1 , 215-226.

GILHOOLY, K. J., \& LOGIE, R. H. (1982). Word age-of-acquisition and lexical decision making. Acta Psychologica, 50, 21-34.

GilHOOLY, K. J., \& WatsON, F. L. (1981). Word age-of-acquisition effects: A review. Current Psychological Research, 1, 269-286.

GRAINGER, J. (1990). Word frequency and the neighborhood frequency effects in lexical decision and word naming. Journal of Memory \& Language, 29, 228-244.

Grainger, J., \& Ferrand, L. (1994). Phonology and orthography in visual word recognition: Effects of masked homophone primes. Journal of Memory \& Language, 33, 218-233.

Hofland, K., \& Johansson, S. (1982). Word frequencies in British and American English. Bergen: Norwegian Computing Centre for the Humanities.

Howard, D., \& Franklin, S. (1989). Missing the meaning? A cognitive neuropsychological study of the processing of words by an aphasic patient. Cambridge, MA: MIT Press.

Humphreys, G. W., RidDOCH, M. J., \& QuinLAN, P. T. (1988). Cascade processes in picture identification. Cognitive Neuropsychology, $\mathbf{5}$, 67-103.

INHOFF, A. W., \& RAYNER, K. (1986). Parafoveal word processing during eye fixations in reading: Effects of word frequency. Perception \& Psychophysics, 40, 431-439.

JESCHENIAK, J. D., \& LEVELT, W. J. M. (1994). Word frequency effects in speech production: Retrieval of syntactic information and of phonological form. Journal of Experimental Psychology: Learning, Memory, \& Cognition, 20, 824-843.

JohNSTON, R. S., \& MCDERMOTT, E. A. (1986). Suppression effects in thyme judgement tasks. Quarterly Journal of Experimental Psychology, 38A, 111-124.

Just, M. A., \& CarPenter, P. A. (1980). A theory of reading: From eye fixations to comprehension. Psychological Review, 87, 329-354.

KLEIMAN, G. M. (1975). Speech recoding in reading. Journal of Verbal Learning \& Verbal Behavior, 14, 323-339.

KROLL, J. F., \& Merves, J. S. (1986). Lexical access for concrete and abstract words. Journal of Experimental Psychology: Learning, Memory, \& Cognition, 12, 92-107.

KUČERA, H., \& FRANCIS, W. (1967). Computational analysis of presentday American-English. Providence, RI: Brown University Press.

Lachman, R., Shaffer, J. P., \& Hennrikus, D. (1974). Language and cognition: Effects of stimulus codability, name-word frequency, and age-of-acquisition on lexical reaction time. Journal of Verbal Learning \& Verbal Behavior, 13, 613-625.

LAMBON-RALPH, M. A. (1994). The locus of age-of-acquisition: Effects in word recognition and production. Unpublished undergraduate dissertation, University of York.

Lukatela, G., \& Turvey, M. T. (1994a). Visual lexical access is initially phonological: Evidence from associative priming by words, homophones and pseudohomophones. Journal of Experimental Psychology: General, 123, 107-128.

LuKatela, G., \& TuRVEY, M. T. (1994b). Visual lexical access is initially phonological: 2 . Evidence from phonological priming by homophones and pseudohomophones. Journal of Experimental Psychology: General, 123, 331-353.

Lyons, A. W., Teer, P., \& Rubenstein, H. (1978). Age-at-acquisition and word recognition. Journal of Psycholinguistic Research, 7, 179187.

MASON, M. (1978). Print to sound in mature readers as a function of reader ability and two forms of orthographic regularity. Memory \& Cognition, 6, 568-581.

MCCANN, R. S., \& BESNER, D. (1987). Reading pseudohomophones: Implications for models of pronunciation assembly and the locus of the word frequency effects in naming. Journal of Experimental Psychology: Human Perception \& Performance, 13, 13-24.

McCann, R. S., Besner, D., \& DavelaAR, E. (1988). Word recognition and identification: Do word frequency effects reflect lexical access? Journal of Experimental Psychology: Human Perception \& Performance, 14, 693-706.

McClelland, J. L., \& RumelhaRT, D. T. (1981). An interactive activation model of context effects in letter preparation: I. An account of basic findings. Psychological Review, 88, 375-407.

MCRAE, K., JARED, D., \& SEIDENBERG, M. S. (1990). On the roles of frequency and lexical access in word naming. Journal of Memory \& Language, 29, 43-65.

MONSELL, S. (1991). The nature and locus of word frequency effects in reading. In D. Besner \& G. W. Humphreys (Eds.), Basic processes in reading: Visual word recognition (pp. 148-197). Hillsdale, NJ: Erlbaum.

Monsell, S., Dolyle, M. C., \& HaGgaRd, P. N. (1989). Effects of frequency on visual word recognition tasks: Where are they? Journal of Experimental Psychology: General, 118, 43-71.

MoRRIs, P. E. (1981). Age of acquisition, imagery, recall, and the limitations of multiple-regression analysis. Memory \& Cognition, 9, 277 282.

Morrison, C. M., Chappell, T. M., \& Ellis, A. W. (1997). Age of acquisition norms for a large set of object names and their relation to adult estimates and other variables. Quarterly Journal of Experimental Psychology, 50A, 528-559.

Morrison, C. M., \& ELLIS, A. W. (1995). Roles of word frequency and 
age of acquisition in word naming and lexical decision. Journal of Experimental Psychology: Learning, Memory, \& Cognition, 21, 116133.

Morrison, C. M., Ellis, A. W., \& Quinlan, P. T. (1992). Age of acquisition, not word frequency, affects object naming, not object recognition. Memory \& Cognition, 20, 705-714.

Morton, J. (1969). Interaction of information in word recognition. $P_{s y-}$ chological Review, 76, 165-178.

MORTON, J. (1979). Facilitation in word recognition: Experiments causing change in the logogen model. In P. A. Kolers, M. E. Wrolstad, \& H. Bouma (Eds.), Processing of visible language: Vol. 1 (pp. $107-$ 156). London: Plenum.

Moscovitch, M., \& Umiltà, C. A. (1990). Modularity and neuropsychology: Modules and central processes in attention and memory. In M. F. Schwartz (Ed.), Modular deficits in Alzheimer-type dementia (pp. 1-59). Cambridge, MA: MIT Press.

Nagy, W., Anderson, R. C., Schommer, M., Scott, J. A., \& StallMAN, A. C. (1989). Morphological families in the internal lexicon. Reading Research Quarterly, 24, 262-282.

OlDFIELD, R. C., \& WingFiELD, A. (1965). Response latencies in naming objects. Quarterly Journal of Experimental Psychology, 17, 273 281

ParkiN, A.J. (1982). Phonological recoding in lexical decision: Effects of spelling-to-sound regularity depend on how regularity is defined. Memory \& Cognition, 10, 43-53.

Parkin, A. J. (1984). Redefining the regularity effect. Memory \& Cognition, 12, 287-292.

RaTCLIFF, R. (1993). Methods for dealing with reaction time outliers. Psychological Bulletin, 114, 510-532.

Roodenrys, S., Hulme, C., Alban, J., Ellis, A. W., \& Brown, G. D. A. (1994). Effects of word frequency and age of acquisition on short-term memory span. Memory \& Cognition, 22, 695-701.

Rubenstein, H., Lewis, S. S., \& RubENSTEIN, M. A. (1971). Evidence for phonemic recoding in visual word recognition. Journal of Verbal Learning \& Verbal Behavior, 10, 645-657.

SCHWANENFlugel, P. J., \& SHOBEN, E. J. (1983). Differential context effects in the comprehension of abstract and concrete verbal materials. Journal of Experimental Psychology: Learning, Memory, \& Cognition, 9, 82-102.

Seidenberg, M. S., \& MCClelland, J. L. (1989). A distributed developmental model of word recognition and naming. Psychological Review, 96, 523-568.

SeidenberG, M. S., Petersen, A., MacDonald, M. C., \& Plaut, D. C.
(1996). Pseudohomophone effects and models of word recognition Journal of Experimental Psychology: Learning, Memory, \& Cognition, 22, 48-62.

Seidenberg, M. S., Waters, G. S., Barnes, M. A., \& Tanenhaus, M. K. (1984). When does irregular spelling or pronunciation influence word recognition? Journal of Verbal Learning \& Verbal Behavior, 23, 383-404.

Strain, E., Patterson, K., \& Seidenberg, M. S. (1995). Semantic effects in single-word naming. Journal of Experimental Psychology: Learning, Memory, \& Cognition, 21, 1140-1154.

Turner, J. E., Valentine, T., \& Ellis, A. W. (1998). Contrasting effects of age of acquisition and word frequency on auditory and visual lexical decision. Memory \& Cognition, 26, 1282-1291.

VAN ORDEN, G. C. (1987). A ROWS is a ROSE: Spelling, sound, and reading. Memory \& Cognition, 15, 181-198.

VAN ORDEN, G. C. (1991). Phonologic mediation is fundamental to reading. In D. Besner \& G. W. Humphreys (Eds.), Basic processes in reading: Visual word recognition (pp. 77-103). Hillsdale, NJ: Erlbaum.

VAN ORden, G. C., Johnston, J. C., \& HaLE, B. L. (1988). Word identification in reading proceeds from print to sound to meaning. Journal of Experimental Psychology: Learning, Memory, \& Cognition, 14, 371-386

Van Orden, G. C., Pennington, B. F., \& Stone, G. O. (1990). Word identification in reading and the promise of a subsymbolic psycholinguistics. Psychological Review, 97, 488-522.

WHALEY, C. P. (1978). Word-nonword classification times. Journal of Verbal Learning \& Verbal Behavior, 17, 143-154.

\section{NOTES}

1. The use of this form of articulatory suppression is far less common, and the only other study to have made use of it of which we are aware is an unpublished undergraduate thesis by Lambon-Ralph (1994), supervised by A. W. Ellis, at the University of York. This involved a semantic categorization task, in which printed words had to be categorized as either naturally occurring or man made. Early- and late-acquired words (matched for frequency) and high- and low-frequency words (matched for AoA) were compared under conditions of no suppression, nonverbal suppression (humming music), and verbal suppression (reciting a nursery rhyme). AoA effects were seen in the first two conditions, but were eliminated by verbal suppression; frequency had no reliable effect in any of the three conditions.

2. We thank Bob Lorch for kindly pointing this out. 
APPENDIX

The Words Used in the Five Experiments

\begin{tabular}{|c|c|c|c|c|c|c|c|c|c|c|c|}
\hline & $\mathrm{KF}$ & Con. & Imag. & AoA & $\mathrm{L}$ & & KF & Con. & Imag. & AoA & $\mathrm{L}$ \\
\hline \multicolumn{6}{|c|}{ Early-Acquired, High-Frequency Words } & \multicolumn{6}{|c|}{ Late-Acquired, High-Frequency Words } \\
\hline men & 763 & 5.86 & 5.87 & 2.36 & 3 & student & 131 & 5.49 & 6.03 & 4.81 & 7 \\
\hline step & 131 & 5.08 & 4.83 & 2.67 & 4 & union & 182 & 4.49 & 5.26 & 5.03 & 5 \\
\hline breakfast & 53 & 5.76 & 5.86 & 2.33 & 9 & sex & 84 & 5.12 & 5.84 & 4.5 & 3 \\
\hline fight & 98 & 4.55 & 5.43 & 2.61 & 5 & novel & 59 & 5.29 & 5.47 & 4.75 & 5 \\
\hline page & 66 & 5.71 & 5.55 & 2.67 & 4 & mass & 110 & 3.97 & 4.84 & 4.58 & 4 \\
\hline march & 120 & 4.4 & 4.97 & 2.69 & 5 & moral & 142 & 2.2 & 3.41 & 5.39 & 5 \\
\hline weather & 69 & 4.39 & 5.37 & 2.92 & 7 & text & 60 & 4.98 & 4.37 & 4.86 & 4 \\
\hline win & 55 & 3.64 & 4.54 & 2.69 & 3 & secretary & 191 & 5.76 & 5.63 & 4.56 & 9 \\
\hline shoulder & 61 & 5.89 & 5.77 & 2.64 & 8 & science & 131 & 3.66 & 4.23 & 4.58 & 7 \\
\hline find & 399 & 3.51 & 3.7 & 2.72 & 4 & industry & 171 & 4.79 & 4.99 & 4.92 & 8 \\
\hline land & 217 & 6.04 & 5.66 & 2.86 & 4 & president & 382 & 5.26 & 5.72 & 4.58 & 9 \\
\hline newspaper & 65 & 5.76 & 6.16 & 2.92 & 9 & income & 109 & 4.29 & 4.75 & 5.06 & 6 \\
\hline close & 234 & 3.91 & 4.2 & 2.83 & 5 & rate & 209 & 3.08 & 3.11 & 4.56 & 4 \\
\hline people & 847 & 5.4 & 5.48 & 2.81 & 6 & $\operatorname{tax}$ & 197 & 4.45 & 4.46 & 4.69 & 3 \\
\hline cousin & 51 & 5.02 & 4.78 & 2.78 & 6 & degree & 125 & 4.06 & 5.21 & 5.08 & 6 \\
\hline brother & 73 & 5.85 & 5.89 & 2.19 & 7 & professor & 57 & 5.49 & 5.87 & 5.19 & 9 \\
\hline$M$ & 206.4 & 5.05 & 5.25 & 2.67 & 5.6 & $M$ & 146.2 & 4.52 & 4.95 & 4.82 & 5.9 \\
\hline$S D$ & 251.8 & 0.87 & 0.69 & 0.21 & 2.0 & $S D$ & 80.2 & 0.97 & 0.86 & 0.27 & 2.1 \\
\hline \multicolumn{6}{|c|}{ Early-Acquired, Low-Frequency Words } & \multicolumn{6}{|c|}{ Late-Acquired, Low-Frequency Words } \\
\hline fairy & 4 & 4.33 & 5.36 & 2.42 & 5 & glare & 7 & 4.39 & 5.36 & 4.44 & 5 \\
\hline pet & 8 & 5.57 & 5.89 & 2.19 & 3 & albatross & 0 & 6.21 & 5.83 & 5.28 & 9 \\
\hline rhyme & 3 & 4.34 & 4.75 & 2.53 & 5 & ting & 0 & 3.5 & 3.16 & 4.92 & 4 \\
\hline smash & 4 & 4.02 & 5.18 & 2.78 & 5 & soprano & 6 & 4.97 & 5.35 & 5.19 & 7 \\
\hline fisherman & 5 & 5.67 & 6.1 & 2.89 & 9 & cologne & 9 & 5.76 & 5.86 & 4.94 & 7 \\
\hline berry & 9 & 5.73 & 5.51 & 2.89 & 5 & rogue & 1 & 4.24 & 4.78 & 4.44 & 5 \\
\hline rattle & 5 & 5.49 & 5.54 & 2.61 & 6 & delta & 7 & 4.94 & 4.99 & 5.54 & 5 \\
\hline peep & 2 & 3.88 & 4.37 & 2.89 & 4 & saxophone & 4 & 6.24 & 6.02 & 5.19 & 9 \\
\hline knitting & 1 & 5.83 & 5.78 & 2.86 & 8 & cue & 0 & 5.32 & 4.48 & 5.54 & 3 \\
\hline greed & 3 & 2.62 & 4.2 & 2.94 & 5 & urchin & 0 & 5.68 & 5.29 & 4.69 & 6 \\
\hline scratch & 9 & 5.23 & 5.43 & 2.69 & 7 & crypt & 1 & 5.73 & 5.53 & 5.39 & 5 \\
\hline tablespoon & 6 & 5.87 & 6 & 2.58 & 10 & crucifix & 3 & 5.64 & 5.76 & 4.75 & 8 \\
\hline hush & 4 & 3.96 & 4.67 & 2.46 & 4 & $\operatorname{disc}$ & 6 & 5.53 & 5.75 & 4.47 & 4 \\
\hline vase & 4 & 5.95 & 5.63 & 2.97 & 4 & urn & 2 & 5.51 & 5.1 & 4.42 & 3 \\
\hline satchel & 0 & 5.93 & 5.8 & 2.97 & 7 & gush & 1 & 3.96 & 4.83 & 4.53 & 4 \\
\hline elf & 0 & 4.37 & 5.43 & 2.72 & 3 & marvel & 6 & 2.93 & 4.1 & 4.89 & 6 \\
\hline$M$ & 4.2 & 4.92 & 5.35 & 2.71 & 5.6 & $M$ & 3.3 & 5.03 & 5.14 & 4.91 & 5.6 \\
\hline$S D$ & 2.8 & 1.00 & 0.57 & 0.23 & 2.1 & $S D$ & 3.1 & 0.97 & 0.75 & 0.40 & 1.9 \\
\hline
\end{tabular}

Note-KF, (Kučera \& Francis, 1967) word frequency; Con., concreteness; Imag., imageability; AoA, age-of-acquisition ratings (from Gilhooly \& Logie, 1980); L, number of letters in the word.

(Manuscript received August 6, 1997;

revision accepted for publication July 23, 1998.) 